\title{
Is Buzz an Efficient Means to Sell Goods?
}

\author{
Olivier Lefebvre \\ Olivier Lefebvre Consultant, Paris75005, France
}

\begin{abstract}
The goal of the paper is to compare the efficiency of two selling methods, perfect information (advertising) and buzz. One has to speak of two different kinds of goods: standard goods and experience based goods. Standard goods can be sold using perfect information or buzz and this allows the comparison. The model for the sale when perfect information is used is provided by game theory (Bertrand Equilibrium). Buzz is modeled thanks to the notion of cognitive bias ("laziness") from Khaneman. The result of the comparison is that buzz is not advantageous, no matter the concerned party (sellers or customers). Experience based goods like videogames can be sold only using buzz. One can model the sale of videogames when the first version is free (it occurs frequently). Again, using buzz is not very efficient (but in the case of videogames it cannot be avoided).
\end{abstract}

Key words: Game theory, economic competition, customer's behavior, videogames industry.

\section{Introduction}

We start from an anecdote told by Raymonde Moulin in her book "The market of painting in France". In Paris between the two World Wars there were two famous art dealers, Kahnweiler and Wildenstein (the both sold the paintings of young Picasso). Their strategies were very different:

Kahnweiler bought paintings from young talented painters at a low price, then sold them quickly to trigger buzz and make the painter renowned. Then the price of the paintings of this painter increased, and again he bought and sold his paintings ...

Wildenstein also bought paintings from young painters who were not yet renowned, then stored them, selling them perhaps after twenty years when the prices have very much increased. His motto was: "boldness at the time of purchase, patience at the time of sale" [1].

This anecdote shows that a strategy relying on buzz can succeed.

Therefore to compare the efficiency of the two selling methods, "perfect information" and buzz, is interesting.

Corresponding author: Olivier Lefebvre, Ph. D., research fields: game theory, telecommunications policy, regulation in the telecommunications sector.
But before presenting the framework of the paper we have to define what "perfect information" and buzz are. Also we have to give details on the kinds of goods which are concerned.

\subsection{Defining "Perfect Information" and Buzz}

"Perfect information" means advertising campaigns which allow the consumers to know the existence of the products (services), their main characteristics and their utility. When each consumer knows the utility of each product sold, he (she) buys the product providing the higher net utility (the difference between the utility and the price) or he (she) does not buy any product if all the net utilities are negative.

The buzz is merely the word to mouth. But it depends on the mindset of the consumers: they can be curious, have a mindset focused on research, or be "lazy". Suppose there are two products in competition, $\mathrm{A}$ and $\mathrm{B}$. If the consumers are curious, when the buzz about A (B) reaches one of them he will seek information on B (A). He will be informed about the two products. If the consumers are lazy, when one of them is reached by the buzz about A (B) he pays attention to the product A (B) only. Perhaps he buys A (B) or not. If he does not buy A (B) he is no more interested in the buzz about these products. This 
behavior is not in accordance with his interest. It is the consequence of his laziness. In the words of Kahneman this consumer uses his System 1 (intuition, problems easy to solve) and not his System 2 (logical reasoning). In his book Thinking fast and slow Kahneman studies laziness. We quote him: "Laziness is deeply embedded in our nature". He speaks also of "cognitive ease". The behavior of the lazy consumer who is disappointed (he has been reached by the buzz concerning a product and did not buy it) and is no more interested by any product of this kind, is explained by the "anchoring effect". An "anchor" is a first judgment which influences definitively the ideas on some topic [2].

Clearly, the comparison which makes sense is between perfect information and buzz, the consumers being lazy (if they are curious the outcome is the same).

\subsection{What Kind of Good Is Concerned?}

There are three kinds of goods:

Trust based goods require this condition: the honesty of the seller is well known. Examples are a solicitor, an arbitrator or a broker. The only strategy is to become renowned thanks to buzz.

Experience based goods require to have been tested by the consumer, before he can know the utility. Examples are some medical treatments and videogames. The only strategy possible for sellers is buzz.

Standard goods allow consumers knowing easily their utility as soon some information is available. There are many examples (cars, tours, houses etc.). Only these goods allow a comparison between the two selling methods, perfect information and buzz.

\subsection{Framework of the Paper}

We shall consider four cases:

Case 1: We resume the story of Kahnweiler and Wildenstein. It is to show thanks to a simple imagined example that the strategy which banks on buzz (that of
Kahnweiler) can allow winning more money that the one neglecting buzz (that of Wildenstein).

Case 2: Here we consider a single seller using buzz. It allows modeling the buzz in a simple way. Also, we state that the seller will decrease his price (compared to the case of perfect information) to win time. It is to accelerate the buzz. The consumers are winning.

Case 3: Here two sellers in competition use buzz, but the consumers are supposed curious. The outcome is the same than when perfect information is chosen. We shall use game theory and justify this choice. The case 3 allows us to present what is called Bertrand competition in game theory.

Case 4: Two competitors sell their products using buzz, the consumers being supposed to be lazy. To model the buzz leads to an equation of the Volterra Lotka kind. We demonstrate that one Nash equilibrium, at least, exists ${ }^{1}$.

The formulas giving the two profits are:

$$
\begin{aligned}
\mathrm{P}_{1}=\mathrm{N}\left(\mathrm{p}_{1}-\mathrm{c}_{1}\right) \mathrm{D}_{1}\left(\mathrm{p}_{1}, 1\right) \mathrm{x}_{0} 1^{\mathrm{D} 1(\mathrm{p} 1,1)} & \\
& \mathrm{P}_{2}=\mathrm{N}\left(\mathrm{p}_{2}-\mathrm{c}_{2}\right) \mathrm{D}_{2}\left(1, \mathrm{p}_{2}\right) \mathrm{y}_{0} \mathrm{l}^{\mathrm{D} 2(1, \mathrm{p} 2)}(1)
\end{aligned}
$$

where the $p_{i}$ and the $c_{i}$ are the prices and the costs, $N$ is the total number of consumers, $\mathrm{Nx}_{0}$ and $\mathrm{Ny}_{0}$ are the numbers of informed consumers at the start ("sowing") and $D_{1}$ and $D_{2}$ are the demands, functions of $p_{1}$ and $p_{2}$ (considered as probabilities).

The quantity 1 is given by:

$$
\mathrm{x}_{0} \mathrm{l}^{\mathrm{D} 1(\mathrm{p} 1,1)}+\mathrm{y}_{0} \mathrm{l}^{\mathrm{D} 2(1, \mathrm{p} 2)}=1 .
$$

In the general case the calculations are too complex to state that this equilibrium is the single one. But in the symmetrical case (that we shall define) it is simpler: one can demonstrate that there is a single Nash equilibrium. This allows the comparison between the two Nash equilibriums, when perfect information is used and when buzz is used. It appears that the advantages of buzz are uncertain. It is not that the prices will increase very much. But one of the two parties (the sellers and the consumers) will lose. If the prices increase, the consequence is that the consumers'

1 It is in pure strategies (which are not probabilistic). Otherwise there is always one Nash equilibrium, at least, if mixed strategies are possible (it is the Kakutani theorem). 
surplus decreases. If the prices decrease, the consequence is that the profits of the sellers decrease. Possibly the two parties lose, but one at least loses.

Our conclusion is that we shall live during a long time in a world where there are experts in advertising and marketing. When standard goods are concerned, either the sellers or the consumers benefit from "perfect information" (compared to buzz). Of course, the definition of buzz is somewhat arbitrary (the "laziness" of the consumers). But it gives an idea of the consequences of laziness of the consumers when buzz is used. Advertising is intrusive but it obliges the consumers to pay attention to the characteristics of the products sold. If one fears too much power for the experts in advertising, the solution is consumerism: associations give advices to consumers on the quality of the products, their characteristics, their prices ...

\subsection{Plan of the Paper}

The plan of the paper is as follows:

(1) Presentation of the case 1 ;

(2) Presentation of the case 2;

(3) Presentation of the case 3;

(4) Presentation of the case 4;

(5) Tractable examples;

(6) The case of several pricings;

(7) The sale of videogames;

(8) Conclusion.

\section{Case 1: The Story of Kanhweiler and Wildenstein}

We imagine two phases: during the phase 1 the price of the paintings increases from 100 to 150 and during the phase 2 it increases from 150 to 200 . Kahnweiler buys more paintings because he makes the prices increase and the painter works more. Of course he sells the paintings to trigger buzz and make the prices increase. In the example Kahnweiler wins more money $(11,000)$ than Wildenstein $(10,000)$. The two strategies are shown in the Table 1:

\section{Case 2: A Single Firm Sells Its Product}

A firm sells its product at a price $\mathrm{p}$ and has a cost $\mathrm{c}$. Its profit is $P(p)=(p-c) D(p)$, where $D(p)$ is the function of demand, decreasing and concave. At the instant $t$ there are $\mathrm{N} \times(\mathrm{t})$ consumers reached by the buzz ( $\mathrm{N}$ is the total number of consumers). The number of consumers having bought the product is $\mathrm{x}$ (t) D (p). They are "active agents" of the diffusion of the buzz. Therefore:

$$
\mathrm{N} \mathrm{dx}=\mathrm{k}_{0} \mathrm{x}(\mathrm{t}) \mathrm{D}(\mathrm{p}) \mathrm{N}[1-\mathrm{x}] \mathrm{dt} \text {. }
$$

The number of consumers newly informed about the product (during the time $\mathrm{dt}$ ) is some proportion of the encounters between those informed and having bought the product and those not informed. These encounters are the efficient encounters. Possibly the constant $\mathrm{k}_{0}$ encapsulates the use of social networks and Internet (there are more efficient encounters). Finally:

$\mathrm{x}=1 / 1+\mathrm{Ke}^{-\mathrm{kt}}$, with $\mathrm{K}=1-\mathrm{x}_{0} / \mathrm{x}_{0}$ and $\mathrm{k}=\mathrm{k}_{0} \mathrm{D}(\mathrm{p})$. (4)

At the start there is a small number $\mathrm{N} \mathrm{x}_{0}$ of informed consumers (it is a kind of "sowing"). When $t$ $\rightarrow \infty, x \rightarrow 1$. After time enough the value of the profit is $P(p)$. The seller has chosen $\mathrm{p}_{\mathrm{m}}$ : $\operatorname{Max}_{\mathrm{p}} \mathrm{P}(\mathrm{p})$.

There is no difference between the outcomes of perfect information and buzz.

But suppose that the sales last some time, and that the profit is acquired after the time $T_{0}: P(p)=(p-c)$ $\mathrm{D}(\mathrm{p}) \times\left(\mathrm{p}, \mathrm{T}_{0}\right)$. If $\mathrm{p}=\mathrm{p}_{\mathrm{m}}$,

$\partial \mathrm{P} / \partial \mathrm{p}\left(\mathrm{p}_{\mathrm{m}}\right)=\left(\mathrm{p}_{\mathrm{m}}-\mathrm{c}\right) \mathrm{D}\left(\mathrm{p}_{\mathrm{m}}\right) \partial / \partial \mathrm{p}\left[\mathrm{x}\left(\mathrm{p}, \mathrm{T}_{0}\right)\right]$. This expression is negative, as it is seen from Eq. (4): when $\mathrm{p}$ increases, $\mathrm{k}$ decreases.

Table 1 The strategies of Kahnweiler and Wildenstein.

\begin{tabular}{lll}
\hline & Phase 1 & Phase 2 \\
\hline Prices & $100 \rightarrow 150$ & $150 \rightarrow 200$ \\
Kahnweiler & $\begin{array}{l}\text { Buys } 100 \text { paintings at the price } 100 \text { and sells } \\
\text { them at the price } 150\end{array}$ & $\begin{array}{l}\text { Buys } 120 \text { paintings at the price } 150 \text { and sells } \\
\text { them at the price } 200\end{array}$ \\
Wildenstein & Buys 100 paintings at the price 100 and sells them at the price 200
\end{tabular}


It means that the seller decreases the price to maximize his profit. This is beneficial to consumers (compared to the other choice, perfect information). The explanation is simple: by decreasing the price the seller obtains faster proceeds and wins more money during the time $T_{0}$.

This is confirmed if we consider a discount rate $\delta(0$ $<\delta<1$ ). It means that at the instant $t=0$ a flow of proceeds $\mathrm{q}$ at the instant $\mathrm{t}$ has the value $\mathrm{q} \delta^{\mathrm{t}}$. The formula is: $P(p)=(p-c) D(p) F(p)$, with $F(p)=\int_{0}$ $\rightarrow \infty \mathrm{dx} / \mathrm{dt} \delta^{t} \mathrm{dt}$. The result is obvious. There is no calculation to make. If $p$ decreases $\left(p^{\prime}<p\right)$ the curve $x$ $\left(p^{\prime}, t\right)$ is deduced from the curve $x(p, t)$ thanks to an affinity the coefficient of which is $\mathrm{D}(\mathrm{p}) / \mathrm{D}\left(\mathrm{p}^{\prime}\right)<1$. The same small part of the proceeds (at a level $\mathrm{x}, \mathrm{dx}$ ) is acquired in advance. Therefore the present value is more.

We conclude that the seller decreases his price when he uses buzz in these conditions: (1) the investment lasts some time and there is no discount rate and (2) there is a discount rate and the investment lasts a long time.

Videogames are experience based goods which can be sold only using buzz. Often the sellers provide the first version for free. It is to accelerate the buzz: in Eq. (4) the constant $\mathrm{k}$ is maximal when $\mathrm{p}=0$. After, the game is known and the seller is permanently in touch with the customers thanks to Internet. The customers become regular. The vendor upgrades the game. The successive versions are sold at some price, which allows profit.

\section{Case 3: The Sellers Use Buzz and the Consumers Are "Curious"}

We call these sellers $E_{1}$ and $E_{2}$, their costs being $c_{1}$ and $\mathrm{c}_{2}$. They choose the prices $\mathrm{p}_{1}$ and $\mathrm{p}_{2}$. We consider the "diagram of the utilities": in a plane $\mathrm{Ou}_{1} \mathrm{u}_{2}$ the utilities of the consumers are represented by a point $\left(\mathrm{u}_{1}, \mathrm{u}_{2}\right), \mathrm{u}_{1}$ being the utility of the product 1 and $\mathrm{u}_{2}$ being the utility of the product 2 , for this consumer. We suppose $0 \leq \mathrm{u}_{1} \leq 1$ and $0 \leq \mathrm{u}_{2} \leq 1$, without any loss of generality. We define $\mathrm{p}\left(\mathrm{u}_{1}, \mathrm{u}_{2}\right)$ : the probability that the utilities $\left(\mathrm{u}_{1}, \mathrm{u}_{2}\right)$ of a consumer are such that $\mathrm{u}_{10} \leq$ $\mathrm{u}_{1 \leq \mathrm{u}_{10}}+\mathrm{du}_{1}$ and $\mathrm{u}_{20} \leq \mathrm{u} 2 \leq \mathrm{u}_{20}+\mathrm{du}_{2}$ is $\mathrm{p}\left(\mathrm{u}_{10}, \mathrm{u}_{20}\right) \mathrm{du}_{1}$ $\mathrm{du}_{2}$.

Then we consider three areas:

$A_{1}$ corresponds to the consumers making the purchase of the product 1 , if they are informed about the two products: $\mathrm{u}_{1}-\mathrm{p}_{1} \geq \mathrm{u}_{2}-\mathrm{p}_{2}$ and $\mathrm{u}_{1}-\mathrm{p}_{1} \geq 0$.

$A_{2}$ corresponds to the consumers making the purchase of the product 2 , if they are informed about the two products: $\mathrm{u}_{2}-\mathrm{p}_{2} \geq \mathrm{u}_{1}-\mathrm{p}_{1}$ and $\mathrm{u}_{2}-\mathrm{p}_{2} \geq 0$.

$A_{3}$ corresponds to the consumers making no purchase: $\mathrm{u}_{1}-\mathrm{p}_{1} \leq 0$ and $\mathrm{u}_{2}-\mathrm{p}_{2} \leq 0$.

Now we call $\mathrm{d}_{1}$ and $\mathrm{d}_{2}$ the weights of the two areas $A_{1}$ and $A_{2}: \mathrm{d}_{1}=\int_{\mathrm{A} 1} \mathrm{p}\left(\mathrm{u}_{1}, \mathrm{u}_{2}\right) \mathrm{du}_{1} \mathrm{du}_{2}, \mathrm{~d}_{2}=\int_{\mathrm{A} 2} \mathrm{p}\left(\mathrm{u}_{1}, \mathrm{u}_{2}\right)$ $\mathrm{du}_{1} \mathrm{du}_{2}$ (See Fig. 1 where the point $\mathrm{M}_{1}$ belongs to $A_{1}$, the point $\mathrm{M}_{2}$ belongs to $A_{2}$ and the point $\mathrm{M}_{3}$ belongs to $\left.A_{3}\right)$.

The demands $\mathrm{D}_{1}\left(\mathrm{p}_{1}, \mathrm{p}_{2}\right)$ and $\mathrm{D}_{2}\left(\mathrm{p}_{1}, \mathrm{p}_{2}\right)$ of the two products are $\mathrm{D}_{1}=\mathrm{N} \mathrm{d}_{1}$ and $\mathrm{D}_{2}=\mathrm{N} \mathrm{d}_{2}$.

We can write the formulas of the profits (in the case of perfect information):

$$
\begin{aligned}
& \mathrm{P}_{1}\left(\mathrm{p}_{1}, \mathrm{p}_{2}\right)=\left(\mathrm{p}_{1}-\mathrm{c}_{1}\right) \mathrm{D}_{1}\left(\mathrm{p}_{1}, \mathrm{p}_{2}\right) \\
& \left.\quad \mathrm{P}_{2}\left(\mathrm{p}_{1}, \mathrm{p}_{2}\right)=\left(\mathrm{p}_{2}-\mathrm{c}_{2}\right) \mathrm{D}_{2} \mathrm{p}_{1}, \mathrm{p}_{2}\right)
\end{aligned}
$$

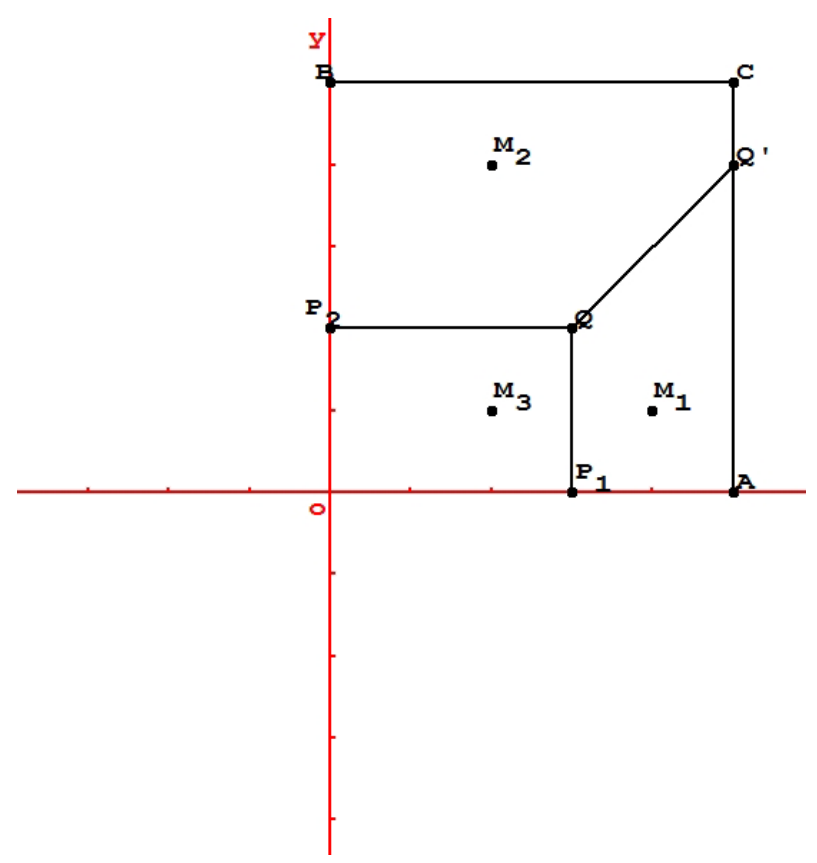

Fig. 1 The three areas $A_{1}, A_{2}$ and $A_{3}$ are shown. 
The equations giving $\mathrm{p}_{1}$ and $\mathrm{p}_{2}$ corresponding to Nash equilibrium are:

$$
\partial \mathrm{P}_{1} / \partial \mathrm{p}_{1}=0 \text { and } \partial \mathrm{P}_{2} / \partial \mathrm{p}_{2}=0 \text {. }
$$

Here we have to explain why Nash equilibrium is interesting when it exists.

When Nash equilibrium exists, is single and stable, it is the only state of the economic sector which is stable: there is no reason for the players to change their choices. But equilibrium only would be too simple [3]. The economic sector is described in a better way by the term "equilibrium of equilibriums" [3]. The two other possible states are price wars and tacit collusion:

Tacit collusion consists in high prices chosen (without any agreement) when the sector is in bad condition. Of course it allows higher profits.

Price war is chosen by one player to end tacit collusion because his profit increases when he decreases his price and gets a big market share. But when he is imitated all the profits in the sector will decrease and soon or later the price war will end [4].

The two states, price war and tacit collusion are unstable, while Nash equilibrium is stable. The sector oscillates between the two unstable states and is often at Nash equilibrium. Therefore, Nash equilibrium is a coarse indicator of the state of the economic sector.

This kind of competition, when the competitors choose their prices, is called Bertrand competition and is well known in game theory [5].

There are a few conditions concerning the diagram of the utilities, $\mathrm{D}_{1}$ and $\mathrm{D}_{2}$, allowing Nash equilibrium which exists, is single and stable [6]. We suppose that these conditions are fulfilled. More, the reaction functions $\mathrm{R}_{1}\left(\mathrm{p}_{2}\right)$ and $\mathrm{R}_{2}\left(\mathrm{p}_{1}\right)$ have positive slopes. The prices are "strategic complements" meaning that if a player increases his price, the response of the other is to increase his own price.

The definitions of the reaction functions are:

$\mathrm{p}_{1}=\mathrm{R}_{1}\left(\mathrm{p}_{2}\right), \mathrm{p}_{1}: \operatorname{Max}_{\mathrm{p} 1} \mathrm{P}_{1}\left(\mathrm{p}_{1}, \mathrm{p}_{2}\right)$

$\mathrm{p}_{2}=\mathrm{R}_{2}\left(\mathrm{p}_{1}\right), \mathrm{p}_{2}: \operatorname{Max}_{\mathrm{p} 2} \mathrm{P}_{2}\left(\mathrm{p}_{1}, \mathrm{p}_{2}\right)$

$\left(p_{1}=R_{1}\left(p_{2}\right)\right.$ is the best response of the player 1 to $\mathrm{p}_{2}$, that is to say he maximizes his profit).

Also, the stable equilibrium should be chosen by short seeing firms (meaning firms anticipating only the consequences of one step).

One checks: $\partial \mathrm{D}_{1} / \partial \mathrm{p}_{2}=\partial \mathrm{D}_{2} / \partial \mathrm{p}_{1}$, therefore the integral $\int-D_{1} d p_{1}-D_{2} d p_{2}$ can be calculated between two points $\left(u_{1}, u_{2}\right)$ and $\left(u_{1}^{\prime}, u_{2}\right)$ along any path. It gives the variation of the consumers' surplus.

Now we model the buzz. If $x(0 \leq x \leq 1)$ is the proportion of informed consumers there are $\mathrm{x}\left(\mathrm{D}_{1}+\right.$ $\mathrm{D}_{2}$ ) agents of diffusion of the buzz. When a consumer is reached by the buzz he will buy the product corresponding to the maximal net utility, no matter the product bought by the consumer having informed him. Or he buys nothing if the two net utilities are negative. Therefore:

$\mathrm{N} \mathrm{dx}=\mathrm{k}_{0} \mathrm{x}\left(\mathrm{D}_{1}+\mathrm{D}_{2}\right) \mathrm{N}(1-\mathrm{x}) \mathrm{dt}$.

If $\mathrm{k}=\mathrm{k}_{0}\left(\mathrm{D}_{1}+\mathrm{D}_{2}\right)$ we find the same equation than in case $2: \mathrm{dx}=\mathrm{kx}(1-\mathrm{x}) \mathrm{dt}$.

After some time, $\mathrm{x} \approx 1$ and the two profits are:

$\mathrm{P}_{1}=\left(\mathrm{p}_{1}-\mathrm{c}_{1}\right) \mathrm{D}_{1}$

$\mathrm{P}_{2}=\left(\mathrm{p}_{2}-\mathrm{c}_{2}\right) \mathrm{D}_{2}$.

The outcome of using the buzz, when the consumers are "curious" is the same than when "perfect information" is used.

\section{Case 4: The Sellers Use Buzz and the Consumers Are "Lazy"}

The firms in competition sell their products thanks to buzz, the consumers being "lazy". When a consumer not yet reached by the buzz meets a purchaser of the product 1 , he buys it, or does not buy it. His carelessness has two aspects: (1) if he buys the product 1 he could have preferred to buy the product 2 and (2) if he does not buy the product 1, he could have bought the product 2, which he does not because he is not informed about the product 2 . He pays attention to the buzz a single time. He will no more be interested in the buzz. Therefore the equations describing the diffusion of the buzz are:

$\mathrm{N} \mathrm{dx}=\mathrm{k}_{0}\left[\mathrm{~N} \mathrm{x} \mathrm{W}_{1}\right] \mathrm{N}(1-\mathrm{x}-\mathrm{y}) \mathrm{dt}$ 
$\mathrm{N} d \mathrm{y}=\mathrm{k}_{0}\left[\mathrm{~N} \mathrm{y} \mathrm{W}_{2}\right] \mathrm{N}(1-\mathrm{x}-\mathrm{y}) \mathrm{dt}$. The proportions of the consumers who are reached by the buzz about the two products are $\mathrm{x}$ and $\mathrm{y} . \mathrm{W}_{1}$ and $\mathrm{W}_{2}$ are the weights of the areas in the diagram of the utilities corresponding to $\mathrm{u}_{1}-\mathrm{p}_{1} \geq 0$ and $\mathrm{u}_{2}-\mathrm{p}_{2} \geq 0$.

This is shown in the Fig. 2.

These equations are of the kind "competitive Lotka Volterra" and the solution is:

$$
\left(\mathrm{x} / \mathrm{x}_{0}\right)^{\mathrm{W} 1}=\left(\mathrm{y} / \mathrm{y}_{0}\right)^{\mathrm{W} 2}, \mathrm{x}=\mathrm{x}_{0} \mathrm{f}(\mathrm{t})^{\mathrm{W} 1}, \mathrm{y}=\mathrm{y}_{0} \mathrm{f}(\mathrm{t})^{\mathrm{W} 2}, \mathrm{f}(\mathrm{t})
$$

being the solution of the equation:

$$
\mathrm{f}^{\prime}(\mathrm{t})=\mathrm{k} \mathrm{f}(\mathrm{t})\left[1-\mathrm{x}_{0} \mathrm{f}(\mathrm{t})^{\mathrm{W} 1}-\mathrm{y}_{0} \mathrm{f}(\mathrm{t})^{\mathrm{W} 2}\right] \text {. }
$$

After a time long enough $\mathrm{f}(\mathrm{t})=1$, given by: $1-\mathrm{x}_{0}$ $1^{\mathrm{W} 1}-\mathrm{y}_{0} 1^{\mathrm{W} 2}=0$.

The values $\mathrm{x}_{0}$ and $\mathrm{y}_{0}$ are the values of $\mathrm{x}$ and $\mathrm{y}$ at the start ("sowing"). There are a small number of consumers reached by the buzz at the start. To simplify we shall suppose $\mathrm{x}_{0}=\mathrm{y}_{0}=\mathrm{k}$, $\mathrm{k}$ being small. If $\mathrm{k}<1 / 2, \mathrm{~K}=1 / \mathrm{k}>2$ and $\mathrm{l}>1,1^{\mathrm{W} 1}>1,1^{\mathrm{W} 2}>1$, since: $1^{\mathrm{W} 1}+1^{\mathrm{W} 2}=\mathrm{K}$.

The formulas giving the profits are:

$$
\begin{aligned}
& \mathrm{P}_{1}=\mathrm{N}\left(\mathrm{p}_{1}-\mathrm{c}_{1}\right) \mathrm{D}_{1}\left(\mathrm{p}_{1}, 1\right) \mathrm{x}_{0} \mathrm{l}^{\mathrm{D} 1(\mathrm{p} 1,1)} \\
& \mathrm{P}_{2}=\mathrm{N}\left(\mathrm{p}_{2}-\mathrm{c}_{2}\right) \mathrm{D}_{2}\left(1, \mathrm{p}_{2}\right) \mathrm{y}_{0} \mathrm{1}^{\mathrm{D} 2(1, \mathrm{p} 2)} .
\end{aligned}
$$

Here $\mathrm{D}_{1}\left(\mathrm{p}_{1}, 1\right)$ is the same than $\mathrm{W}_{1}$ and $\mathrm{D}_{2}\left(1, \mathrm{p}_{2}\right)$ is the same than $\mathrm{W}_{2}$.

The value of 1 is given by $1^{\mathrm{W} 1}+1^{\mathrm{W} 2}=\mathrm{K}$ (if $\mathrm{x}_{0}=\mathrm{y}_{0}=$ $\mathrm{k})$.

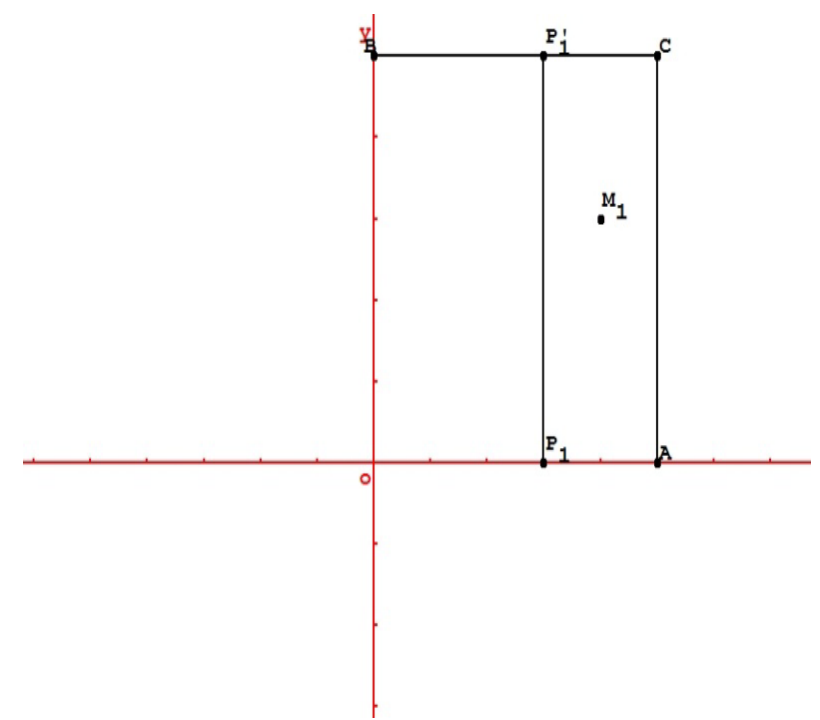

Fig. 2 The area $u_{1}-p_{1} \geq 0$, where is the point $M_{1}$, has a weight $W_{1}$.
Now we examine the topic of Nash equilibrium: $\partial$ $\mathrm{P}_{1} / \partial \mathrm{p}_{1}=0, \partial \mathrm{P}_{2} / \partial \mathrm{p}_{2}=0$.

The function $\partial \mathrm{P}_{1} / \partial \mathrm{p}_{1}$ is given by (we suppose $\mathrm{N}$ $=1$ and we neglect $\mathrm{k})$ :

$$
\partial \mathrm{P}_{1} / \partial \mathrm{p}_{1}=\partial\left(\mathrm{p}_{1}-\mathrm{c}_{1}\right) \mathrm{w}_{1} / \partial \mathrm{p}_{1} \mathrm{1}^{\mathrm{W} 1}+\left(\mathrm{p}_{1}-\mathrm{c}_{1}\right) \mathrm{w}_{1} \partial \mathrm{l}^{\mathrm{W} 1}
$$

In the general case the calculations are very complex. One can demonstrate the existence of Nash equilibrium (in pure strategies). The reaction function $\mathrm{R}_{1}\left(\mathrm{p}_{2}\right)$ is defined. But one must suppose that the Nash equilibrium is single.

But the symmetrical case is very interesting because the calculations are easier. It is when the diagram of the utilities is symmetrical $\left(\mathrm{p}\left(\mathrm{u}_{1}, \mathrm{u}_{2}\right)=\mathrm{p}\left(\mathrm{u}_{2}, \mathrm{u}_{1}\right)\right)$ and the costs are the same $\left(c_{1}=c_{2}=c\right)$.

One can demonstrate that there is a single Nash equilibrium.

Since a single Nash equilibrium exists in the symmetrical case, it allows the comparison between the outcomes of perfect information (used as a selling method) and buzz. We compare the characteristics of the two equilibriums.

First, the prices when buzz is chosen are not very high. They are between the cost $c$ and the price $p_{m}$ chosen by a firm which is the single in the market.

But the disadvantages of buzz appear if we compare the prices (of the two equilibriums):

If the prices are higher, it is sure that the consumers' surplus decreases.

There are several reasons:

(1) Even if we do not take into account $x$ and $y$ (which are equal to $1 / 2$ in the symmetrical case) the consumers' surplus is less. It is obvious if we use the integral $\int-D_{1} d p_{1}-D_{2} d p_{2}$ between the two points $\left(p_{1}\right.$, $\left.\mathrm{p}_{2}\right)$ and $\left(\mathrm{p}_{1}, \mathrm{p}_{2}\right), \mathrm{p}_{1}>\mathrm{p}_{1}, \mathrm{p}_{2}>\mathrm{p}_{2}$.

Or we can reason on a single increase of $\mathrm{p}_{1}$ or $\mathrm{p}_{2}$ (it is obvious that the consumers' surplus decreases).

(2) Some consumers lack. The number of lacking consumers is $\mathrm{N}\left(\mathrm{D}_{1}+\mathrm{D}_{2}-\mathrm{w}_{1} \mathrm{x}-\mathrm{w}_{2} \mathrm{y}\right)$. No customer lacks in the area $\mathrm{u}_{1}-\mathrm{p}_{1}>0$ and $\mathrm{u}_{2}-\mathrm{p}_{2}>0$. But customers lack in the areas $\mathrm{u}_{1}-\mathrm{p}_{1}>0, \mathrm{u}_{2}-\mathrm{p}_{2}<0$ and 
$\mathrm{u}_{1}-\mathrm{p}_{1}<0, \mathrm{u}_{2}-\mathrm{p}_{2}>0$.

(3) Among the consumers represented by points in the area $\mathrm{u}_{1}-\mathrm{p}_{1}>0$ and $\mathrm{u}_{2}-\mathrm{p}_{2}>0$ all make a purchase but some should have preferred the product they have not bought. For instance a consumer who has been reached by the buzz about the product 1 has bought it, but he would have preferred to buy the product 2 , should he have been informed about this product (it corresponds to $\mathrm{u}_{2}-\mathrm{p}_{2}>\mathrm{u}_{1}-\mathrm{p}_{1}$ and $\mathrm{u}_{1}-\mathrm{p}_{1}>$ $0)$.

The first reason (why the consumers 'surplus is less) is displayed on the Fig. 3:

The other reason why the consumers' surplus is less is displayed on the Fig. 4:

If the prices are lower, it is sure that the sellers' surplus decreases.

The point representing the equilibrium moves on the bisector towards the origin of the axis, O. If we do not take into account $x$ and $y$, the profits decrease. It is easy to prove. We consider $\mathrm{P}_{1}(\mathrm{p}, \mathrm{p})$ with $\mathrm{p}<\mathrm{p}_{\mathrm{N}}, \mathrm{p}_{\mathrm{N}}$ being the equilibrium price $\left(p_{1}=p_{2}=p_{N}\right)$. The derived function $d / d p P_{1}(p, p)$ is positive because it is the sum of two positive terms: $d / d p P_{1}=\partial / \partial 1 P_{1}+\partial /$ $\partial 2 \mathrm{P}_{1}$. More, the values of $\mathrm{x}$ and $\mathrm{y}$ being $1 / 2$, the profits (at the Nash equilibrium corresponding to buzz) are less than when the prices are the same, perfect information being chosen.

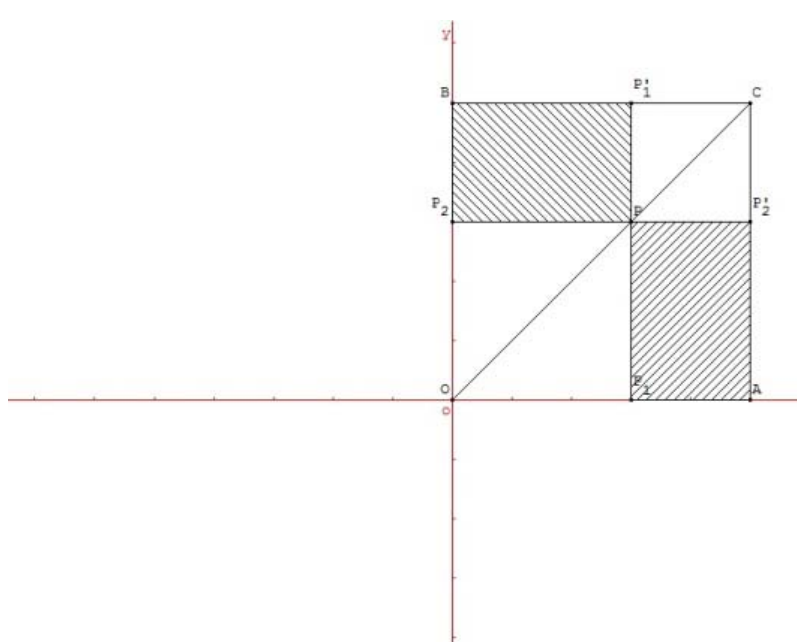

Fig. 3 When buzz is used, in the symmetrical case, one customer on two lacks in the hatched areas. It is one of the reasons why the consumers' surplus is less.

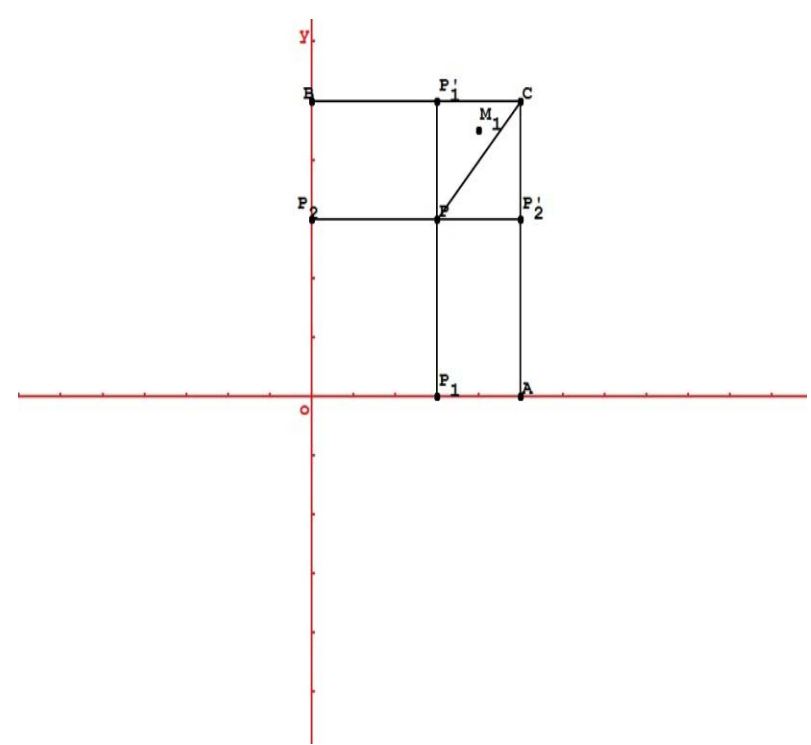

Fig. 4 The customer represented by the point $M_{1}$ prefers the product 2 to the product 1 . Should he be informed on the two products he would buy the product 2 . But when buzz is used, he is reached by the buzz concerning the product 1. Being "lazy" he buys it. The consequence is that his surplus is less.

More accurately, one consumer on two lacks to the firm $E_{1}$ in the area $u_{1}-p_{1}>0, u_{2}-p_{2}<0$. And one consumer on two lacks to the firm $E_{2}$ in the area $u_{2}-$ $\mathrm{p}_{2}>0, \mathrm{u}_{1}-\mathrm{p}_{1}<0$.

Our conclusion is that choosing the buzz makes always one party (sellers or consumers) lose. Either the consumers' surplus decreases (if prices increase). Or the profits of the sellers decrease (if prices decrease). And possibly, the two parties are losing.

Now two tractable examples are presented.

\section{Tractable Examples}

There are tractable examples. All can be calculated. The reaction functions exist and have a positive slope, there is a single stable Nash equilibrium, concerning the Bertrand equilibrium. And concerning the use of buzz the price of the single Nash equilibrium can be calculated.

Example 1 is when $\mathrm{p}\left(\mathrm{u}_{1}, \mathrm{u}_{2}\right)=1\left(\right.$ and $0<\mathrm{u}_{1}<1,0$ $\left.<\mathrm{u}_{2}<1\right)$.

Example 2 is when $\mathrm{u}_{1}+\mathrm{u}_{2}=1$, the density of probability is on the segment $[(0,1),(1,0)]$ and homogeneous (equal to $1 / \sqrt{ } 2$ ). 
In the two examples, the costs are equal to 0 .

For instance the values of the equilibrium prices in the example 1 are:

$\mathrm{p}=\sqrt{2}-1$ (Bertrand equilibrium)

$p=1 / 2+1 / 2 \log K / 2$ (when buzz is used).

The equilibrium price when buzz is used depends on the sowing.

One can check that for some values of $\mathrm{K}$ (the sowing) the two parties (sellers and consumers) are losing.

It is the same in the case of the example 2.

\section{The Case of Several Pricings}

If there are successive pricings we can suppose that the first pricing is $\left(\mathrm{p}_{1 \mathrm{~N}}, \mathrm{p}_{2 \mathrm{~N}}\right)$ which corresponds to Nash equilibrium. Then the values of $\mathrm{x}$ and $\mathrm{y}$ are definitively $\mathrm{x}_{\mathrm{N}}=\mathrm{x}\left(\mathrm{p}_{1 \mathrm{~N}}, \mathrm{p}_{2 \mathrm{~N}}\right)$ and $\mathrm{y}_{\mathrm{N}}=\mathrm{y}\left(\mathrm{p}_{1 \mathrm{~N}}, \mathrm{p}_{2 \mathrm{~N}}\right)$. The formulas for the profits (it concerns the second pricing, the third pricing etc.) are:

$$
\begin{aligned}
& \mathrm{P}_{1}=\mathrm{N}\left(\mathrm{p}_{1}-\mathrm{c}_{1}\right) \mathrm{w}_{1} \mathrm{x}_{\mathrm{N}} \\
& \mathrm{P}_{2}=\mathrm{N}\left(\mathrm{p}_{2}-\mathrm{c}_{2}\right) \mathrm{w}_{2} \mathrm{y}_{\mathrm{N}}
\end{aligned}
$$

For instance the good has to be bought again because of obsolescence.

The pricing should be $\left(\mathrm{p}_{1 \mathrm{~m}}, \mathrm{p}_{2 \mathrm{~m}}\right)$. These prices correspond to the price chosen when one of the two sellers is the single in the market (that is to say when the other chooses the price 1).

Therefore:

$$
\begin{aligned}
& \mathrm{P}_{1}=\mathrm{N}\left(\mathrm{p}_{1 \mathrm{~m}}-\mathrm{c}_{1}\right) \mathrm{w}_{1} \mathrm{x}_{\mathrm{N}} \\
& \quad \mathrm{P}_{2}=\mathrm{N}\left(\mathrm{p}_{2 \mathrm{~m}}-\mathrm{c}_{2}\right) \mathrm{w}_{2} \mathrm{y}_{\mathrm{N}} .
\end{aligned}
$$

In the symmetrical case only one is sure that there is a single Nash equilibrium (during the first phase, when the buzz occurs), and the formulas are: $P_{1}=1 / 2 N$ $\left(p_{m}-c\right) w$ and $P_{2}=1 / 2 N\left(p_{m}-c\right) w$.

It is not Nash equilibrium. The profit of one seller does not depend on the choice of the other. Each seller maximizes his profit as if he was alone in the market. In the Eq. (6) the profit of one seller depends on the choice of the other because 1 depends on the two prices $\left(1^{\mathrm{W} 1}+1^{\mathrm{W} 2}=\mathrm{K}\right.$ means that 1 is a function of $\mathrm{p}_{1}$ and $\mathrm{p}_{2}$ ).
If we compare the outcomes of "perfect information" and buzz when there are successive pricings, the conclusion is that the consumers' surplus is less when buzz is chosen: (1) the prices are higher, since the equilibrium prices of the Bertrand competition are lower than $\mathrm{p}_{1 \mathrm{~m}}$ and $\mathrm{p}_{2 \mathrm{~m}}$ and (2) one has to take into account $\mathrm{x}_{\mathrm{N}}$ and $\mathrm{y}_{\mathrm{N}}$.

\section{The Sale of Videogames}

Videogames are experience based goods which should be sold only using buzz. When the first version is free in any case: $x=1 / 2$ and $y=1 / 2$. When the prices are 0 , no consumer lacks, since there is no areas $u_{1}-$ $\mathrm{p}_{1} \geq 0, \mathrm{u}_{2}-\mathrm{p}_{2} \leq 0$ or $\mathrm{u}_{1}-\mathrm{p}_{1} \leq 0, \mathrm{u}_{2}-\mathrm{p}_{2} \geq 0$. But it is another story when there is the second pricing, the third pricing etc. The seller knows his customers, is permanently in touch with them, upgrades his product and chooses prices allowing profit. The sellers should choose $\mathrm{p}_{1 \mathrm{~m}}$ and $\mathrm{p}_{2 \mathrm{~m}}$ :

$$
\begin{aligned}
& P_{1}=1 / 2 N\left(p_{1 m}-c_{1}\right) w_{1} \\
& P_{2}=1 / 2 N\left(p_{2 m}-c_{2}\right) w_{2}
\end{aligned}
$$

Customers lack: one on two in the area $u_{1}-p_{1 m} \geq 0$, $\mathrm{u}_{2}-\mathrm{p}_{2 \mathrm{~m}} \leq 0$ (concerning the seller 1) and in the area $\mathrm{u}_{1}$ $-\mathrm{p}_{1 \mathrm{~m}} \leq 0, \mathrm{u}_{2}-\mathrm{p}_{2 \mathrm{~m}} \geq 0$ (concerning the seller 2 ).

But this lack of consumers (compared to the consumers who would have bought the products, should perfect information have been used) is inevitable. A videogame, being an experience based good, can be sold only thanks to buzz.

Therefore, if a seller spends very much money when he creates the game, it is not to acquire more customers. In any case he will have N / 2 customers. But these customers will have higher utilities. Later, when the seller chooses $\mathrm{p}_{1 \mathrm{~m}}$, this price can be higher. It allows more profit.

And why to deliver the first version freely? It is not to acquire more customers: later, when the price $p_{1 m}$ will be chosen, all the customers having downloaded the game, whose utility is less than $p_{1 m}\left(u_{1}-p_{1 m}<0\right)$ will lack. But the freeness allows a faster buzz.

The sellers avoid any competition. But it is not 
deliberate. Again, videogames being experience based goods can be sold only using buzz. In the first phase delivering the game is free, because it makes the second phase (when the pricing allows profit) occur sooner. In this phase a seller can upgrade the game and sell it at higher price, but he keeps his customers. $\mathrm{He}$ is in touch with them and can inform them about the new versions of the game. He cannot gain customers from the other seller, since he is not in touch with them.

\section{Conclusion}

To compare the efficiency of the two selling methods, advertising and buzz, one uses two tools, the Kahneman's theory on cognitive biases and game theory:

The Kahneman's theory allows describing the effect of buzz: the consumers are "lazy".

Game theory allows the comparison because the single Nash equilibrium (if it exists) is a coarse indicator of the state of the sector. When advertising is used, there is a single, stable Nash equilibrium (Bertrand equilibrium). And when buzz is used, one demonstrates that there is a single Nash equilibrium, in some conditions (the symmetrical case) ${ }^{2}$.

The result of the comparison is that buzz is disadvantageous: one party, the sellers or the consumers, is losing, and possibly the two are losing. The reason is simple: when buzz is used, there lack customers.
In the tractable examples, in some conditions the sellers and the consumers are losing.

Therefore standard goods are sold by sellers using advertising. Only experience based goods like videogames are sold by sellers using buzz.

The sale of videogames when the first version is delivered for free is easily modeled. That buzz is not advantageous appears. In the symmetrical case, one checks that the existence of two rival videogames which are sold has no effect, from the point of view of competition. All the surpluses (the sellers' surplus, that is to say the joint profit, and the consumers' surplus) are the same. At the opposite, when advertising is used, the existence of two products sold increases the consumers' surplus.

\section{References}

[1] Moulin, R. 1967. "Le marché De la Peinture en France ( The market of painting in France )." Editions de Minuit.

[2] Kahneman, D. 2011. "Thinking Fast and Slow." Farrar Strauss and Giroux.

[3] Morin, E. 1981. "La Nature De La Nature (The nature of nature)." Editions du Seuil.

[4] Tirole, J. 1988. The Theory of Industrial Organization. Cambridge: MIT Press.

[5] Baye, R., and Kovenock, D. 2008. The Palgrave Dictionary of Economics Article "Bertrand Competition". New York: Macmillan Publishers.

[6] Lefebvre, O. 2014. Game Theory and the Stakes in the Telecommunications Industry. Saarbrucken: Lambert Academic Publishing.

\footnotetext{
${ }^{2}$ If this equilibrium is stable or not does not matter. Stability of Nash equilibrium matters when groping is possible: after several steps, each competitor chooses the equilibrium price. The Bertrand equilibrium is stable. But when buzz is used, there is no successive pricings, each competitor taking into account the price chosen by the other. When the pricings after the first pricing occur, each seller has his captive customers. Nash equilibrium during the first pricing means that each seller will not regret his choice, given the other's choice.
} 